\title{
Denver Development Screening Test
}

National Cancer Institute

\section{Source}

National Cancer Institute. Denver Development Screening Test. NCI Thesaurus. Code C81245.

A test developed at the University of Colorado Medical Center to assess the developmental status of infants and children from birth to six years of age. 